\title{
- $\sigma=a$ B $r=a-g$.
}

\section{Promessas de Amor e Seko: as matrizes do ekcesso e 0}

agenciamento do público no primeiro episódio de The L Ulord

Érica Sarmet ${ }^{1}$

\section{Resumo}

Este artigo busca trabalhar a presença estratégica das matrizes do excesso e dos gêneros do corpo, em especial do melodrama e da pornografia, na série The L Word. Tal presença, intensificada no primeiro episódio, promove distintos agenciamentos do público, instaurando promessas de arcos narrativos e lugares de fala políticos que estrategicamente ampliam o público alvo da série. No caso específico de The $L$ Word, tais estratégias são particularmente importantes, pois sua temática - a vida de mulheres lésbicas e bissexuais levanta questões usualmente desconsideradas no campo televisivo, que tende a privilegiar narrativas alinhadas às lógicas da sociedade patriarcal heterocêntrica. Nesse sentido, acreditamos que os múltiplos agenciamentos de The $L$ Word convidam a um engajamento passional importante para a um só tempo garantir o sucesso comercial da série e sua legitimidade junto ao movimento LGBT.

Palauras-chaue: Ficção Seriada; Engajamento Passional; Agenciamento, Gêneros do Corpo; The L Word.

\section{IกTRODUÇก̃O}

Duas mulheres estão conversando à beira de uma piscina, à noite. Elas estão em uma cobertura, e dali vê-se as luzes da cidade de Los Angeles. Uma revela para a outra que aquele lugar é um lugar íntimo, especial. Vemos em closes a luz da piscina refletida em

${ }^{1}$ Érica Sarmet é graduanda em Estudos de Mídia na Universidade Federal Fluminense (UFF). Este artigo é resultado da pesquisa de iniciação científica Sensações em série - a matriz do excesso e o imperativo do engajamento nas ficções seriadas, sob orientação da Profa. Dra. Mariana Baltar, com financiamento PIBIC/UFF 2009-2011. A pesquisa é desenvolvida no âmbito do Nex - Núcleo de Estudos do Excesso nas Narrativas Audiovisuais, grupo de pesquisas estruturado com verba Faperj, através do edital Auxílio Instalação. 
seus rostos, e a câmera acompanha o movimento de seus corpos se aproximando, o toque das mãos, e enfim, o beijo entre as duas.

Essa cena entre as personagens Marina (Karinna Lombard) e Jenny Schecter (Mia Kirshner) está presente no primeiro episódio da série de TV a cabo americana The $L$ Word, e nela estão acionados elementos que agem como promessas de arcos narrativos não só para a temporada, mas para a série como um todo, uma vez que ela está sendo pela primeira vez apresentada ao público.

Dentre esses elementos está o uso estratégico de marcas próprias de gêneros da matriz popular do excesso, tais quais os closes e a troca de olhares, típicos da matriz melodramática; a antecipação da referência aos códigos da pornografia, (acionados na cena seguinte, em que as duas personagens fazem sexo) presentes não só no âmbito da linguagem (enquadramentos, mise-en-scène, trilha), mas na própria narrativa da série, que em muitos momentos aproxima o sexo lésbico do fetiche; além disso, o fato de as duas personagens estarem em uma cobertura na cidade de Los Angeles reitera o arco narrativo central da série, que é a representação de um grupo específicos de indivíduos: mulheres bonitas, homossexuais, classe média alta que vivem na cidade de Los Angeles, segunda maior cidade dos Estados Unidos.

O primeiro episódio de uma série de TV possui a responsabilidade não só de despertar no público o interesse pela série por meio das promessas articuladas ao longo do episódio, mas também fazer com que o espectador aceite o convite que aquela narrativa lhe faz de acompanhá-la. The L Word é uma série de TV que aborda a vida de um grupo de amigas lésbicas e bissexuais que vivem na cidade de Los Angeles, Califórnia. Criada por Ilene Chaiken, teve seis temporadas que foram exibidas de 2004 a 2009 pelo canal a cabo Showtime. No Brasil e na América Latina, a série foi ao ar de 2005 a 2010 pelo canal a cabo Warner Channel, inicialmente domingo, às 23 horas.

É relevante citar que os cinco primeiros episódios exibidos pelo Warner Channel tiveram cenas de sexo cortadas e diálogos censurados, de maneira a evitar uma possível reação negativa do público da América Latina, tido como mais conservador ${ }^{2}$. Mesmo não contendo cenas de sexo mais gráficas nem palavrões, a série entrou na grade de exibição do Warner Channel aos domingos, 23h, o que nos leva a pensar que a temática lésbica por

${ }^{2} \mathrm{O}$ site thelwordbr.com.br fez uma relação das cenas cortadas no primeiro episódio, que podem ser conferidas em http://www.thelwordbr.com.br/cortes.html. 
si só justificaria, aos olhos do canal, o horário (Nucci, Carvalho \& Lopes de Melo, 2008). Posteriormente, a série conseguiu ser incluída no primetime do canal (horário nobre), mas sempre depois das $23 \mathrm{~h}$, já havendo sido exibida nesse mesmo horário às segundas-feiras, e depois a 0h, às quartas-feiras.

Através da análise do primeiro episódio de The L Word e sua relação com a primeira temporada, pretendo entender como o primeiro episódio pode agenciar distintos públicos a partir de promessas de arcos narrativos e convites ao engajamento passional vinculados ao modo de excesso próprio dos "gêneros do corpo" - no caso de The L Word, o melodrama e a pornografia - que, como já mostrei, é uma estratégia central na experiência da serialização (Sarmet, 2010: 2) ${ }^{3}$ Também procuro explicar a importância dos múltiplos agenciamentos de The L Word, que tentaram garantir, ao mesmo tempo, o sucesso comercial da série e sua legitimidade junto ao movimento LGBT.

Robin Nelson (2006) divide o agenciamento do público em agenciamentos contextuais e textuais. $\mathrm{O}$ agenciamento contextual refere-se a elementos como a escolha do canal (no caso de $L$ Word, canais a cabo que, por serem pagos, são acessíveis a uma parcela reduzida da população), da grade de programação (horário tardio de exibição, porém ainda dentro do primetime), dentre outros fatores.

$\mathrm{O}$ agenciamento textual refere-se a componentes como a intertextualidade e marcas de reconhecimento na estrutura narrativa, a exemplo da escalação da atriz Jennifer Beals, protagonista de Flashdance (1983) e identificada enquanto estrela heterossexual dos anos 80, para interpretar a personagem Bette Porter; e elementos extradiegéticos que atuam como agentes de legitimação política da série, como o fato de a criadora e produtora executiva, Ilene Chaiken, ser assumidamente lésbica e de alguns diretores e atores serem advindos do "New Queer Cinema",4 (Ladendorf, 2010: 272)

${ }^{3}$ De forma a garantir uma relação de engajamento com o público, as narrativas pautadas por essa lógica de serialização acabam por incorporar na temática, e sobretudo nas estratégias narrativas, características próprias de gêneros vinculados à uma matriz popular do excesso (BARBERO, 2001), definidos por Linda Williams (1991) como "gêneros do corpo". Para entender melhor o papel dos 'gêneros do corpo' na serialização e seus usos, ver Sarmet, 2010.

${ }^{4} \mathrm{O}$ conceito de 'New Queer Cinema' diz respeito a um específico cenário de produção independente do cinema americano nos anos 90, na qual diretores gays, lésbicas e transgêneros investiram em uma prática discursiva positiva sobre a homossexualidade, em um momento em que a população LGBT sofria as agruras da discriminação frente a expansão da epidemia da AIDS ao redor do mundo. O termo 'New Queer Cinema' foi utilizado pela primeira vez pela crítica de cinema e feminista norte-americana B. Ruby Rich, em artigo publicado na revista britânica 'Sight \& Sound', em 1992. 
The $L$ Word é a primeira série na história da televisão cuja narrativa central são as vidas de mulheres lésbicas e bissexuais, tendo por isso já sido tema de diversos estudos sobre televisão e identidade, inclusive de uma antologia dedicada exclusivamente à série (Akass \& McCabe, 2006). Muitos artigos sobre The L Word abordam a representação LGBT em termos políticos específicos, como questões de raça e etnia, bissexualidade, transsexualidade e feminismo.

Eve Sedgwick, em "The L Word: Novelty in Normalcy” (2006), afirma que a série de TV a cabo cria uma "ecologia lésbica", um mundo visível na qual a lésbica existe e segue existindo de diversas maneiras, enquanto indivíduo isolado ou acompanhado, sustentando relações entre si de diferença e semelhança. A presença de diversas personagens lésbicas em uma série de TV, para Sedgwick, dá a ela o potencial de criar representações mais positivas justamente por permitir essas múltiplas representações. (Edwards, 2009: 126)

Rebecca Beirne é autora de diversos artigos que discutem a representação queer na televisão e, em "Fashioning The L Word" (2005), analisa criticamente as duas primeiras temporadas da série e as respostas iniciais do público a ela, em termos de representação de uma identidade lésbica estruturada a partir do estilo de se vestir e das marcas corporais.

Beirne desenvolve em seu artigo a ideia de que a série apresenta uma imagem "fashion" e glamurosa da lesbianidade, "notavelmente utilizando uma imagem lésbica que é historicamente invisível no imaginário cultural do que constitui uma lésbica, através da sua freqüente indistingüibilidade da heterossexualidade”. (Beirne, 2005: 3)

A maior parte das personagens em The L Word segue os padrões de beleza tradicionalmente agenciados pela indústria cultural, sendo, portanto, consideradas bonitas. Além disso, o figurino da série investe em acessórios e roupas caros e historicamente associados à feminilidade, como vestidos, pulseiras e saltos altos. Shane, a personagem mais comumente vestida com acessórios tidos como masculinos, poderia em um primeiro momento ser vista como uma exceção à regra, porém seu estilo negocia muito mais marcas de um visual andrógino do que propriamente masculino - ela, ainda que não siga o padrão das outras personagens, está sim inserida na lógica de representação de uma identidade lésbica "fashion" e glamuralizada que, para Beirne, está muito ligada à noção de "lesbian chic" surgida nos anos 90 . 
Essa representação é vista como oposta ao estereótipo recorrente da lésbica "butch", masculinizada, que praticamente inexiste na série ${ }^{5}$. No entanto, em diversos diálogos de The $L$ Word, a identidade lésbica é identificada como tal justamente a partir dos significantes visuais e comportamentais que marcam a figura da "butch", compreendida no discurso como a lésbica mais autêntica, "real".

Beirne também questiona o fato de a série se propor a mostrar que há lésbicas femininas utilizando-se porém, para isso, de atrizes em sua maioria heterossexuais. Para Beirne, a escolha do elenco reforça percepções hegemônicas da sexualidade lésbica, especialmente a que a vê como um estado liminar, móvel, facilmente retornável à heterossexualidade (Beirne, 2005: 13). A partir dessas práticas, conclui ela, a série contraditoriamente torna a feminilidade lésbica hiper-visível ao mesmo tempo que menos autêntica.

Já Martina Ladendorf (2010) analisa a questão sob a perspectiva de uma comercialização da identidade lésbica em The L Word. Ela tenta responder porque as lésbicas, um grupo anteriormente considerado desinteressante por anunciantes e conglomerados midiáticos, tornaram-se de repente desejáveis.

Ladendorf faz uma rápida revisão histórica da representação da lésbica na cultura da mídia que, quando não completamente ausente, aparece na forma de narrativas com desfechos negativos, nas quais o destino mais comum dado às personagens homossexuais femininas é a morte ou a volta à heterossexualidade. Esse tipo de representação das vidas e relacionamentos lésbicos era bastante comum nos pulp fictions dos anos $50^{6}$, pensados e produzidos para um público-alvo majoritamente composto de homens heterossexuais, mas que também eram amplamente lidos por lésbicas.

Essas mulheres encontravam [e ainda encontram] formas de resistir à negação de sua identidade pela cultura de massa por meio de leituras contra-hegemônicas desses textos hegemônicos, seja se identificando com o personagem masculino no romance heteronormativo ou buscando subtextos homossexuais nos textos dominantes. (Ladendorf, 2010: 271)

\footnotetext{
${ }^{5}$ A entrada de personagens como o transgênero Max na terceira temporada, e a lésbica negra capitã do exército americano, Tasha, na quarta temporada aparecem como uma forma de flexibilização dessas identidades, em uma tentativa da roteirista e produtora executiva Ilene Chaiken de responder às severas críticas feitas a The L Word em suas primeiras temporadas, marcadamente a de que a série contemplava somente o padrão da mulher lésbica branca, classe média e feminina.

${ }^{6}$ Beirne compara o discurso dessas narrativas pulps de 1950 com o de The L Word em "Lesbian Pulp Television: Torment, Trauma and Transformations in The L Word”, 2007.
} 
Stuart Hall, em seu modelo de codificação/decodificação (1980) já falava sobre o papel ativo do público através da interpretação textual, e Andrew Darley (2000) e Elizabeth Evans (2008) argumentam que, apesar do espectador não ter tanta influência sobre o conteúdo da televisão, isso não significa que eles não tenham nenhum tipo de poder para determinar seu engajamento. Como analisa Douglas Kellner (2001),

\footnotetext{
"a cultura da mídia (...) fornece o material com que muitas pessoas constroem o seu senso de classe, de etnia e raça, de nacionalidade, de sexualidade, de 'nós' e 'eles' (...) cria formas de dominação ideológica que ajudam a reiterar as relações vigentes de poder, ao mesmo tempo que fornece instrumental para a construção de identidades e fortalecimento, resistência e luta". (Kellner, 2001: 9, 10)
}

A representação das lésbicas na cultura da mídia é uma negociação, faz parte de uma luta simbólica na qual os espetáculos da mídia criam construções identitárias que exercem influência sobre a sociedade, ao mesmo tempo em que são influenciados por ela. Na cultura do consumo, a visibilidade e inclusão de minorias marginalizadas ocorrem pelo viés do capital - quando um grupo antes socialmente à margem é percebido como um potencial nicho consumidor, então ele passa a ser socialmente mais bem recebido no âmbito do discurso dominante.

Sendo assim, em um contexto do capitalismo tardio e da pósmodernidade/hipermodernidade, em que explorar nichos de mercado com interesses específicos torna-se cada vez mais viável e mais rentável, uma série como The L Word é possível, porém sem deixar de atender aos interesses da indústria cultural: não é apenas a lésbica, é a lésbica fashion, é a identidade lésbica como marca, na qual o estimulo ao consumo está presente não só na mise-en-scène da série (maquiagem, cortes de cabelo, diálogos, música, decoração dos espaços comuns como o café, as casas, etc) mas também em suas estratégias comerciais, como o lançamento de perfumes, maquiagem e jóias da marca $L$ Word.

Por isso, ainda que as críticas de autoras como Beirne e Eve Sedwigck sejam válidas se pensadas numa perspectiva política, o uso de atrizes heterossexuais para interpretar lésbicas - e, principalmente, a publicização desse fato - é uma estratégia de marketing para ampliar o público consumidor de $L$ Word, na qual agencia-se contextualmente um outro tipo de espectador pretendido, mais amplo, que não apenas o da espectadora homossexual. The L Word é um produto da cultura de massa televisiva tal qual qualquer outro e, sendo assim, não está livre de certas amarras impostas pela cultura da mídia e do consumo. 
A identidade lésbica é uma construção cultural e, portanto, os “códigos lésbicos" são ao mesmo tempo construídos e descontruídos na série, pois as realidades sociais e os universos ficcionais estão sempre influenciando um ao outro. The $L$ Word, conclui a autora, "apropriou-se de identidades já existentes e uma cultura LGBT global para obter simultaneamente ganho econômico e um reconhecimento artístico e político na cultura da mídia.” (LADENDORF, 2007, p. 278)

The L Word conquistou tal legitimação com o público por meio do agenciamento de múltiplos elementos, dentre eles gêneros como o melodrama e a pornografia, que são acionados desde o primeiro episódio. Mais adiante, irei desenvolver como as promessas construídas no primeiro episódio agem de maneira a agenciar tais gêneros.

\section{As promessas do primeiro episódio}

"Estética da repetição", como pensado por Omar Calabrese (1987) e mais tarde por Jesus-Martin Barbero (2001), é um conceito que consiste em perceber em narrativas e discursos serializados, uma alternância entre um conjunto de elementos invariáveis pertencentes a um repertório comum dos espectadores, e a introdução de elementos variantes ou novos.

No contexto do consumo da modernidade - e mais adensadamente na hipermodernidade - as narrativas, sobretudo as populares, são marcadas por uma lógica de produção e circulação serializada. Sendo assim, é especialmente importante e estratégico que a narrativa seriada seja ao mesmo tempo repetitiva e inovadora.

A relação da estética da repetição na experiência da serialização surge como um dos elementos narrativos importantes a serem introduzidos já no primeiro episódio, para que o telespectador possa reconhecer os formatos e narrativas que já fazem parte de seu repertório, e também se interessar por o que aquele programa específico tem a oferecer de novo a ele.

Em The L Word, identificamos a repetição temática dos arcos narrativos (traição, fim de relacionamentos, gravidez, discriminação, dentre outros, que se repete não só na tradição discursiva dos seriados, como também na própria série, ao longo das temporadas) e inclusive a repetição de marcas estilísticas do formato, que moldam uma estética própria da série: com exceção do primeiro e segundo episódios, todos os episódios da primeira 
temporada se iniciam com um "random act" ${ }^{7}$, uma sequência "aleatória" que mostra curtas experiências lésbicas em diferentes lugares do mundo e em diferentes épocas, e que percebemos mais tarde relacionar-se direta ou indiretamente com um dos arcos narrativos daquele episódio.

As seqüências encenadas nos "random acts" recuperam, num certo sentido, a história do movimento LGBT, de maneira a funcionarem como um agente legitimador do discurso tanto para o público lésbico, a partir de um ponto de vista político, quanto para o público não-lésbico, que representa o olhar voyeurista. Como afirmam Susan J. Wolfe e Lee Ann Roripaugh,

\begin{abstract}
"Como resultado, as vinhetas em última instância parecem funcionar como um sinal de que os episódios dos quais elas fazem parte são "o negócio real "- o que intensifica a relação voyeurista do público com estes episódios via a insinuação de que a eles está sendo permitido um vislumbre excitante de um "santuário secreto" ficcional, por assim dizer."

(Wolfe \& Roripaugh, 2006: 2)
\end{abstract}

O primeiro episódio de uma narrativa serializada feita para a televisão tem a função de ser uma "promessa a ser vendida" ao telespectador do que aquela série será. O episódio precisa apresentar os personagens e os arcos narrativos pretendidos para a temporada, além de introduzir ganchos e criar expectativas de maneira a promover um agenciamento tanto do público quanto do repertório. No caso de The $L$ Word, reconheço no primeiro episódio o uso de estratégias de adequação da série à normatividade, tanto no plano da linguagem televisiva quanto da prática discursiva, para assim agenciar diferentes espectadores.

Em The L Word, o primeiro episódio inicia-se com planos da cidade de Los Angeles, um travelling por casas luxuosas acompanhado pela logo da série, criando uma expectativa que é quebrada pela aparição do primeiro personagem a ser apresentado ao telespectador Tim (Eric Mabius), um homem branco, jovem e bonito, presumivelmente heterossexual e classe média, que está se mudando para uma casa em Los Angeles.

Essa cena curta já introduz a primeira promessa do episódio, que anuncia: esta é uma série sobre lésbicas, mas não só para lésbicas. Você, homem, você, heterossexual também faz parte dessa narrativa, nós também a construímos pensando em você. O primeiro

${ }^{7}$ Forma como os fãs da série denominavam essas sequências iniciais. O programa manteve esse padrão até meados da terceira temporada, quando as próprias personagens da série passaram a protagonizar essas sequencias de abertura do episódio. 
personagem a ser apresentado ser um homem heterossexual é muito simbólico, pois deixa claro o interesse da série em atrair uma audiência que vá além de um nicho consumidor específico para o qual ela supostamente estaria exclusivamente direcionada.

$\mathrm{Na}$ cena seguinte, vemos duas mulheres deitadas em uma cama, sugerindo a expectativa de um conteúdo sexual que também é logo quebrada pelo início da ação das personagens, na qual são articulados códigos típicos do cotidiano de um casal heteronormativo, como conversas sobre gravidez e trabalho. Não a toa, essa cena aparece em uma montagem paralela de Tim, na casa ao lado, e seu processo para se arrumar e ir para o trabalho.

Primeiras lésbicas a serem apresentadas, Bette (Jennifer Beals) e Tina (Laurel Holloman) desejam ter um filho por meio do processo de inseminação artificial, e vão a um terapeuta de casais para confirmarem que esse é o passo certo a seguir em seu relacionamento, que já dura sete anos. Como uma das promessas do primeiro episódio, está o discurso de que as lésbicas também seguem a moral vigente estabelecida, mostrando ao público que o que ele está vendo é um casal "normal", adequado aos padrões morais hegemônicos, através de uma construção discursiva que aciona elementos do imaginário do que constitui a família tradicional burguesa.

Nessa mesma lógica, encaixe-se a apresentação mais adiante de Kit (Pam Grier), irmã mais velha de Bette. No piloto original que não chegou a ir ao $\operatorname{ar}^{8}$, a personagem de Kit era uma fotógrafa lésbica, a "capitã" que usava tranças e uma boina preta e possuía uma enorme tatuagem cobrindo suas costas com o Chart $^{10}$ original. Já no piloto que foi ao ar, Kit é alcoólatra, viciada, e única personagem heterossexual do elenco principal. Sendo a única heterossexual, Kit representa, num plano simbólico, o papel do indivíduo deslocado, fora dos "padrões morais" vigentes, papel historicamente frequentemente delegado à personagem homossexual em narrativas conservadoras e tradicionais em que há a presença desse personagem.

\footnotetext{
${ }^{8} \mathrm{O}$ episódio piloto é o primeiro episódio produzido de uma série de TV. Ele é inicialmente apresentado aos executivos das emissoras de televisão, funcionando como um teste para saber se aquela série tem potencial para ser comercializada.

${ }_{9}$ Earthlings, Unraired Pilot. A informação/imagens aparece em The L Word Special, especial de uma hora de duração exibido após o último episódio da série. Showtime, 2009.

${ }^{10}$ Chart é uma espécie de quadro contendo os nomes de diversas mulheres conectados por setas aos nomes de outras mulheres com as quais elas já fizeram sexo. Na série, ele foi criado pela personagem Alice, inicialmente montado em uma lousa branca, mas que posteriormente transformou-se numa rede social. $\mathrm{O}$ Chart chegou a existir como rede social real em 2007, com um site voltado para as lésbicas consumidoras da série, o OurChart.com.
} 
O episódio segue para o The Planet, café frequentado pelas personagens, apresentando as outras mulheres que integram o grupo principal da narrativa: Alice Pieszecki (Leisha Hailey), uma jornalista fofoqueira e bissexual, Dana (Erin Daniels), uma tenista promissora que não assume sua homossexualidade por medo de prejudicar a carreira, e Shane McCutcheon (Katherine Moennig), uma jovem cabeleireira estilosa que conquista muitas mulheres.

A cotidianidade familiar, a exemplo de um dos lugares da mediação de que fala Jesus-Martin Barbero (2004), antes considerada irrelevante, é vital para compreender o funcionamento da sociedade na modernidade. A mediação pela cotidianidade familiar representa a situação primordial de reconhecimento, criando a sensação de relações estreitas e de proximidade.

Sendo assim, lugares de familiaridade são uma estratégia comum nas séries de TV, mediando a relação entre os espectadores e a série. No caso da ficção seriada, a cotidianidade familiar se processa por exemplo através da presença de um ambiente familiar, usual - como por exemplo o bar Merlotte's, em True Blood (2008), e o Central Perk, o café de Friends (1994-2004) -, ou de uma ação familiar, repetitiva, a exemplo dos brunches em diversos lugares da cidade de Nova York em Sex and the City (1998-2004). Em The $L$ Word, o uso desse artifício na figura do café The Planet faz com que o público se interesse por uma narrativa atípica no meio televisivo por reconhecer nela o uso de estratégias comuns de uma linguagem tradicional de seriados.

Tim (Eric Mabius), o personagem que vemos nas primeiras cenas do episódio, namora Jenny Schecter (Mia Kishner), uma jovem escritora que carregará um dos mais importantes arcos narrativos para a primeira temporada da série: a descoberta da sexualidade.

De acordo com Robin Nelson (2006), séries e seriados são flexi-narrativos, isto é, seus arcos narrativos são múltiplos e se apresentam como tramas de começo, meio e fim que podem se desenvolver em único episódio e/ou se manter ao longo dos episódios e/ ou da temporada. Como já vimos, este conceito de arco narrativo é emprestado da tradição teórica formalista russa e diz respeito à estrutura da narrativa na correlação com o modo de desenvolvimento de seu enredo, permitindo nomear o desenvolvimento desse enredo independente de sua localização em um único episódio ou ao desdobrar da narrativa. 
No primeiro episódio, é através da personagem de Jenny que o conteúdo sexual da série é mais intensamente explorado: algumas de suas cenas são construídas estrategicamente por uso de códigos conhecidos da pornografia audiovisual, que recorrem a um imaginário pornográfico tanto no âmbito da linguagem - câmera ponto-de-vista de quem está recebendo sexo oral, a própria encenação do sexo, etc - como também na temática, o sexo entre duas mulheres enquanto fetiche.

Em sua casa, Jenny está no jardim quando ouve conversa e risos no quintal vizinho. Ela espia por uma fenda na cerca duas mulheres nadarem nuas na piscina e fazerem sexo. Vemos pelo seu olhar que aquilo a surpreende, mas também a excita. $\mathrm{O}$ fato de Jenny olhar pela fenda não é uma escolha aleatória: a fenda na cerca representa esse novo mundo que se abre para Jenny (e para o público), um mundo "proibido", historicamente, a ela. A fenda representa o proibido e o misterioso que aquela relação homossexual representa para Jenny, e é o olhar voyeurístico do próprio público encenado.

O agenciamento do espectador pelo repertório temático - gravidez, descoberta da sexualidade -, cria ganchos a serem desenvolvidos por meio do uso de códigos do repertório genérico, principalmente do melodrama e da pornografia, que por sua vez criam os ganchos para o engajamento passional e a fidelização do espectador, que pode assumir diferentes posições, dependendo do que está sendo agenciado.

\section{0 agenciamento do melodrama e da pornografia no primeiro episódio}

O melodrama e a pornografia são gêneros que compartilham entre si estratégias comuns vinculadas ao modo de excesso (e, como vimos, são por isso "gêneros do corpo"), convidando o público a estabelecer uma relação com a narrativa pautada no pathos e em uma lógica de engajamento sensório-sentimental. Em The L Word, e especialmente no primeiro episódio, tanto o melodrama como a pornografia estão sendo agenciados estrategicamente não só porque o diálogo com esses gêneros funciona como um convite ao público a engajar-se sensória e sentimentalmente com a narrativa, mas também pelo fato de que um engajamento no pathos é especialmente importante para uma ficção televisiva que foge aos padrões morais tradicionais, bastante conservadores da TV.

A missão que The $L$ Word enfrentou de conquistar o grande público, para além da necessidade óbvia de manter o programa no ar, também era uma missão política, uma vez que se fossem mal sucedidos, as chances de uma nova série de TV sobre lésbicas entrar 
para a grade de programação poderiam ser diminuídas, pois uma narrativa com esse enfoque seria tida como desinteressante para os canais de televisão.

Um dos viés pelos quais o melodrama agencia o espectador é por meio da comoção, que é gerada pela relação de empatia que esse estabelece com o romance encenado em tela. É o espetáculo do corpo visto no ato da sensação e da emoção. No primeiro episódio de The L Word, essa estratégia é evidenciada na construção do relacionamento das personagens de Jenny e Marina, e simbolizada na misè-en-scéne da conversa que precede o primeiro beijo entre elas.

Jenny vai a uma festa na casa de Bette e Tina e lá é apresentada à Marina, uma mulher morena, bonita, com sotaque italiano e dona do café The Planet. Nesta personagem já estão presentes signos de um estereótipo que a identificam enquanto uma mulher sedutora, como sua ascendência italiana e sua postura forte e decidida, antecipando o desenrolar da narrativa, que é pautada por uma obviedade estratégica: ambas descobrem nutrir uma paixão por literatura e uma irresistível atração nasce entre elas.

É na encenação dessa atração que há pela primeira vez no episódio a insinuação visual do desejo sexual lésbico. Para isso, é utilizada uma linguagem típica do melodrama no audiovisual, como close-ups dos olhos e bocas das personagens acompanhados por uma música lenta, que dá o tom romântico e sensual da cena, contribuindo para o convite ao engajamento afetivo do espectador com o par amoroso.

Em um momento posterior no episódio, Jenny e Marina se encontram no The Planet, e a construção discursiva da cena novamente se dá com base na matriz melodramática, com música, diálogos e enquadramentos destacando a troca de olhares, celebrando o par amoroso que está se formando.

Nesse primeiro episódio, podemos identificar o uso da obviedade reiterativa ${ }^{11}$, uma das três categorias do excesso, e mais particularmente do melodrama, (BALTAR, 2007) não só no âmbito dos diálogos, do texto que reforça a todo momento as ideias que a série quer promover, mas também na reincidência da mesma linguagem melodramática sempre que o par amoroso está em cena. Quando Jenny e Marina transam pela primeira vez, ainda nesse episódio, novamente todos os códigos descritos acima são utilizados de maneira estratégica para agenciar o espectador.

\footnotetext{
${ }^{11}$ Obviedade reiterativa é uma das três categorias do excesso definidas por Mariana Baltar. Para saber sobre as categorias do excesso, ver BALTAR, 2007.
} 
O agenciamento do melodrama na narrativa pressupõe uma continuidade tanto do personagem como do arco narrativo, pois o próprio melodrama é utilizado como gancho para a estrutura em série. Sendo assim, os principais arcos narrativos da temporada estão presentes como as principais promessas do primeiro episódio e, justamente por isso, são os arcos narrativos que mais intensamente agenciam os "gêneros do corpo" nessa primeira "amostragem" do que está por vir na série.

A construção da família por meio da gravidez como a principal promessa da temporada, no âmbito do arco narrativo, aproxima-se ao melodrama clássico. A cena de Tina e Bette no consultório do psicanalista também reproduz tanto na misé-en-scène como no texto a lógica da obviedade reiterativa: Bette chega atrasada e tratando no celular de assuntos de trabalho, indicando mais uma vez ser ela a provedora da relação, o que, nos termos da matriz heterossexual (Butler, 2004), representa o papel masculino; esperando por Bette no consultório, está Tina, que largou a carreira de executiva de sucesso para se dedicar exclusivamente à construção de sua família e sua gestação. Identificada como uma personagem passiva e dependente financeiramente de sua cônjuge, representa o papel "feminino" da relação.

Pensada para adequar-se à moral de um consumo "mainstream", The L Word reforça os padrões de gênero esperados nas relações heteronormativas em sua principal e mais estável relação homossexual, pois para atrair esse público consumidor, a série também pode agenciá-lo pela heteronormatividade.

O melodrama inscreve o mundo em um cotidiano que para o público geral pode ser familiar e, por isso, o espectador que o melodrama agencia é o espectador seriado, que aceita o convite do engajamento passional proposto pela narrativa e a consome de forma serializada e excessiva. Para esse espectador, a continuidade dos arcos narrativos é essencial, pois é o que o motiva a assistir um episódio atrás do outro, envolvido pela narrativa e torcendo pelo par amoroso.

Já no diálogo com a pornografia, o mais importante é o número, a coreografia do corpo, pois é ela que está agenciando, pela intensificação do êxtase, da excitação que convida ao gozo, o universo dos espectadores que vão se excitar com o número sexual. No primeiro episódio de The $L$ Word, o agenciamento da pornografia é bastante intenso, de forma a vendê-lo como uma promessa da série: a presença da pornografia está desde 
diálogos explícitos sobre sexo à encenações do número sexual, passando por uma discussão metalinguística sobre o que constitui pornografia e o que a diferencia da arte.

Logo no começo do episódio, vemos um homem masturbar-se para doar seu esperma a Bette e Tina. Não vemos explicitamente a ação, porém um lençol branco é enquadrado, onde vemos a silhueta do homem que se masturba, acompanhado por gemidos de prazer, em um uso estratégico do som na narrativa.

Como já vimos, é no arco narrativo de Jenny e a descoberta de sua sexualidade que o diálogo com a pornografia é mais intenso e exacerbado. $\mathrm{O}$ primeiro número sexual do episódio surge apenas aos quinze minutos e é heteronormativo: Jenny está na cama com Tim e começa a descrever para ele a cena que viu mais cedo na piscina, enquanto tira as roupas de Tim e também as suas. Ela detalha a cena de sexo entre as duas mulheres, um fetiche recorrente no universo da pornografia, de modo a excitar, incitar o desejo sexual no namorado e também no espectador.

Mais tarde, na festa de Bette e Tina, Jenny vai ao banheiro e é seguida por Marina, que adentra o ambiente já a puxando pelo braço e a beijando, enquanto toca seus seios. Jenny, assustada, sai às pressas da festa. A incitação a excitação nessa cena antecipa ${ }^{12}$ a verdadeira encenação do ato sexual da cena seguinte. Jenny vai para casa transar com Tim, pois ele representa o sexo com o seguro, o conhecido, o "correto". Para a construção da performance sexual, são explicitamente utilizados códigos da pornografia audiovisual, como o enquadramento do plano sob o ponto-de-vista de Tim, enquanto Jenny faz sexo oral nele, de forma a excitar o espectador.

O espectador episódico é aquele cujo engajamento com a narrativa se dá somente pelo viés do êxtase. O êxtase, sobretudo no sentido de excitação e estímulo, é potencializado pela visualidade da pornografia, que provoca reações corporais, espasmos que fogem ao controle do espectador (Williams, 2004).

O espectador episódio não necessariamente assiste a todos os episódios, não os vê em ordem cronológica nem se importa com o desfecho dos arcos narrativos presentes na série; ele a acompanha de maneira episódica, sem compromissos, apenas para satisfazer seu desejo de ver encenados novamente códigos que, por serem excitantes, o engajam de maneira passional com aquela narrativa.

\footnotetext{
${ }^{12}$ A antecipação é outra categoria do excesso. Para categorias do excesso, ver BALTAR, 2007.
} 
A discussão explícita da demarcação entre a arte e a pornografia na palestra ministrada por Bette no Centro de Artes da Califórnia quase ao fim do episódio, além de antecipar um arco narrativo que será desenvolvido ao longo da temporada no debate em torno da exposição de arte erótica "Provocations", também age como uma espécie de justificativa à luz das afirmações de que The L Word em si funcionaria como um espetáculo pornográfico (Beirne, 2007:101).

Ao tentar delimitar o lugar da pornografia e o lugar da arte, The L Word tenta legitimar o diálogo que o próprio seriado trava com a pornografia, mas "falha em reconhecer que a linha entre 'arte complexa e provocativa' e pornografia não é fixa, e não pode ser determinada sem considerar o impacto de ambos os contextos e espectadores" (Beirne, 2007: 93).

Através do uso estratégico do melodrama e da pornografia, The L Word é um exemplo de série bem sucedida no agenciamento tanto do espectador seriado quanto do espectador episódico - que, vale ressaltar, não são posições fixas, e sim posições móveis de sujeito -, característica que é especialmente importante no contexto hipermoderno do consumo da ficção seriada, que não se restringe mais ao canal exibidor e ao horário estabelecido pela emissora, nem mesmo à janela: seriados estão sendo produzidos e consumidos em narrativas transmídias, baixados pela internet, gravados na TV digital, armazenados em boxes de DVDs.

O espectador seriado pode assumir o lugar de episódico, ou vice-versa, dependendo de como aquela narrativa irá atuar nas diferentes formas de agenciamento. As promessas do primeiro episódio, portanto, são fundamentais na hora do espectador escolher que posição irá assumir frente àquela série. Em The L Word, o primeiro episódio articula diversas promessas para a temporada que funcionam como mecanismos de legitimação tanto para um público lésbico, sedento por representação na TV, como para um público "mainstream", que se interessa pela série, mas para consumi-la precisa reconhecer nela os códigos com os quais ele está acostumado.

Refletir sobre o engajamento passional e o agenciamento de múltiplos espectadores em The $L$ Word não se trata apenas de apontar a presença das marcas do excesso na narrativa e analisar como se dá esse engajamento, mas principalmente de compreender que 
essas marcas são fundamentais para agenciar o engajamento afetivo do público ${ }^{13}$ numa série que, no contexto da cultura de massa, desafiou - e ainda desafia - os padrões culturais hegemônicos.

\section{Referências Bibliográficas}

BALTAR, Mariana. Realidade lacrimosa: diálogos entre o universo do documentário e a imaginação melodramática. Orientador: Prof. Dr. João Luiz Vieira. Tese (Doutorado), Universidade Federal Fluminense, Curso de Pós-Graduação em Comunicação, 2007. "Metáforas à flor da pele - Os excessivos símbolos que antecipam nossa comoção". Contracampo - revista de Cinema, Rio de Janeiro, n 71/2007, pp. 71. BEIRNE, Rebecca. Fashioning The L Word. http://www.iiav.nl/ezines/web/nebula/2007/no4.4/nobleworld/Beirne.pdf. Acessado em 08/07/2011. . "Dirty Lesbian Pictures: Art and Pornography in The L Word". In: Critical Studies in Television, $\mathrm{n}^{\circ}$ 290/2007, pp. 93-101. "Lesbian Pulp Television: Torment, Trauma and

Transformations in The L Word". Refractory: a journal of entertainment media, $\mathrm{n}^{\circ}$ $11 / 2007$.

BUTLER, Judith. Problemas de Gênero: feminismo e subversão da identidade. Rio de Janeiro: Civilização Brasileira, 2004.

NUCCI, Marina; LOPES DE MELO, Ana Paula; CARVALHO, Marcos. "Conjugalidades homossexuais nos seriados televisivos Queer as Folk e The L Word:

onde gênero e sexualidade se cruzam”.Seminário Fazendo Gênero 8 - ST 39, 2008.

CALABRESE, Omar. Los Replicantes. Barcelona: Análisi. N. 9, 1984.

CASTRO, Daniel. http://www.observatoriodaimprensa.com.br/news/view/daniel-castro28936. Acessado em 09/07/2011.

${ }^{13}$ Conforme demonstramos em meu artigo anterior, já citado, e ao longo da pesquisa de iniciação científica, tal engajamento intensifica o consumo seriado, fidelizando o espectador. 
EDWARDS, Monica Leigh. Transforming images: Media, Sexuality and Everyday Life. Tese (Doutorado), Loyola Chicago University, Programa em Sociologia, dezembro de 2009.

EVANS, Elizabeth Jane. "Character, audience agency and transmedia drama". In: Media, Culture \& Society. Nothingham: Sage Publications, 2008.

KELLNER, Douglas. A cultura da mídia. Bauru: EDUSC, 2001.

LADENDORF, Martina. "Commercialization of Lesbian Identities in Showtime's The L Word". Culture Unbound, n 2/ 2010.

MARTIN-BARBERO, Jesús. Dos meios às mediações - comunicação, cultura e hegemonia. Rio de Janeiro: EdUFRJ, 2001, 2a ed.

NELSON, Robin. “Analsing TV Fiction”. In. CREEBER, Gleen (org). Tele-visions. An introduction to studying television. Bfi Publishing, 2006.

SARMET, Érica. http://www.intercom.org.br/papers/nacionais/2010/resumos/R5-27841.pdf. Acessado em 03/07/2011.

WILLIAMS, Linda. "Film Bodies: gender, genre and excess". In: Film Quarterly, 44/4. Summer, 1991.

WOLFE, Susan J. e RORIPAUGH, Lee Ann. The (In)visible Lesbian: Anxieties of Representation in The L Word. In: Reading The L Word. New York: I.B. Tauris, 2006. 